\title{
Comparison of Intravitreal Bevacizumab Upload Followed by a Dexamethasone Implant versus Dexamethasone Implant Monotherapy for Retinal Vein Occlusion with Macular Edema
}

\author{
Wolfgang J. Mayer Matthias Remy Armin Wolf Daniel Kook Anselm Kampik \\ Michael Ulbig Lukas Reznicek Christos Haritoglou
}

Department of Ophthalmology, Ludwig Maximilians University Munich, Munich, Germany

\section{Key Words}

Macular edema · Retinal vein occlusion - Dexamethasone • Bevacizumab

\begin{abstract}
Purpose: To compare the efficacy and safety of three intravitreal bevacizumab upload injections followed by a dexamethasone implant versus dexamethasone implant monotherapy in eyes with macular edema due to retinal vein occlusion. Methods: Sixty-four eyes of 64 patients were included in this prospective, consecutive, nonrandomized case series: group 1 consisted of 38 patients ( 22 with central retinal vein occlusion, CRVO, 16 with branch retinal vein occlusion, BRVO) treated using a dexamethasone implant (Ozurdex) alone; group 2 consisted of 26 patients (14 CRVO, 12 BRVO) treated with three consecutive intravitreal bevacizumab injections at monthly intervals followed by a dexamethasone implant. In case of recurrence, both cohorts received further dexamethasone implants. Preoperatively and monthly best corrected visual acuity (BCVA, ETDRS), central retinal thickness (Spectralis-OCT), intraocular pressure, and wide-angle fundus photodocumentation (Optomap) were performed. The primary clinical endpoint was BCVA at 6
\end{abstract}

months after initiation of therapy. Secondary endpoints were central retinal thickness and safety of the therapy applied. Results: In group 1, an increase in BCVA of 2.5 ( \pm 1.6$)$ letters in the CRVO and of 13.0 ( \pm 3.2 ) letters in BRVO patients was seen after 6 months, in group 2 of 5.9 ( \pm 0.4 ) letters (CRVO) and 3.8 ( \pm 2.4 ) letters (BRVO), which was not statistically significant. When comparing the two treatment groups with respect to the type of vein occlusion, there was a significant advantage for BRVO patients for the dexamethasone implant monotherapy (BRVO patients in group 1, $\mathrm{p}=$ $0.005)$. Central retinal thickness showed a significant reduction after 6 months only in patients of group 1, both for CRVO $(p=0.01)$ and BRVO $(p=0.003)$. First recurrence after the first dexamethasone implant injection occurred after 3.8 months (mean) in CRVO and 3.5 months in BRVO patients (group 1), versus 3.2 and 3.7 months, respectively, in group 2. In group $1,63.6 \%$ with CRVO and $50 \%$ with BRVO showed an increased intraocular pressure after treatment; in group 2, 57.1\% with CRVO and $50.0 \%$ with BRVO, respectively. Conclusion: In CRVO, there was no difference between the two treatment strategies investigated. However, in BRVO, dexamethasone implant monotherapy was associated with better functional outcome.

Copyright $\odot 2012$ S. Karger AG, Basel

\section{KARGER}

Fax +4161306 1234

E-Mail karger@karger.ch

www.karger.com (c) 2012 S. Karger AG, Basel

$0030-3755 / 12 / 2282-0110 \$ 38.00 / 0$

Accessible online at:

www.karger.com/oph
Wolfgang Mayer, MD

Department of Ophthalmology, Ludwig Maximilians University Munich

Mathildenstrasse 8

DE-80336 Munich (Germany)

E-Mail wolfgang.j.mayer@med.uni-muenchen.de 


\section{Introduction}

Retinal vein occlusion (RVO) is a major cause of visual loss in industrialized countries. Branch retinal vein occlusion (BRVO) is more common than central retinal vein occlusion (CRVO). In both types, the underlying cause of functional deterioration is macular edema. In case of extensive ischemia, neovascularization may occur at the posterior and anterior segment of the eye and lead to severe complications including blindness especially in eyes with CRVO [1]. The pathogenesis of macular edema in RVO is not completely understood. However, some causative factors have been identified such as the role of hydrostatic effects from increased venous pressure, the presence of inflammatory cytokines (e.g., prostaglandins and interleukin-6), and the dysregulation of endothelial tight junction proteins [2], or increased vascular endothelial growth factor (VEGF) expression [3]. Risk factors for RVO include arterial hypertension, hypercholesterolemia, diabetes mellitus, and glaucoma [4].

Recently, two pharmacological treatment regimens have been introduced for the treatment of macular edema associated with RVO including intravitreal injection of VEGF inhibitors such as bevacizumab and corticosteroids such as dexamethasone. While bevacizumab is still off label, a sustained-release dexamethasone implant has been approved [5-7].

The aim of this study was to compare the efficacy and safety of an anti-VEGF upload using bevacizumab followed by a dexamethasone implant versus dexamethasone implant monotherapy as a first-line treatment regimen in patients with CRVO and BRVO.

\section{Materials and Methods}

In this prospective, consecutive, nonrandomized case series 64 eyes of 64 patients with RVO, 39 males and 25 females with a mean age of 68.0 years, were included. Thirty-six patients presented with (nonischemic) CRVO, 28 with BRVO. Only patients with a maximum duration of symptoms of 4 months were included. None of the patients had a known history of glaucoma or corticosteroid response in the past. Patients were recruited between September 2010 and January 2011.

Patients were recruited in a consecutive manner, starting with the combined group. Group 1, including 38 patients (22 with CRVO and 16 with BRVO), was treated with a dexamethasone implant from the beginning. Group 2, including 26 patients (14 CRVO, 12 BRVO), was treated with three consecutive injections of bevacizumab at monthly intervals, followed by a dexamethasone implant at week 16 . Then, both groups received dexamethasone implants once macular edema recurred (fig. 1). Our criteria for retreatment included a loss of best corrected visual acuity
(BCVA) of more than 5 letters (ETDRS) and/or an increase in retinal thickness on optical coherence tomography (OCT) of more than $100 \mu \mathrm{m}$. We measured BCVA (ETDRS chart), central retinal thickness (Spectralis-OCT, Heidelberg Engineering, Germany), as well as intraocular pressure and we took wide-angle retinal images (Optomap OPTOS, Bruchsal, Germany) at initiation of treatment and then at monthly intervals. Fluoresceine angiography was performed initially and after 3 months.

The primary clinical endpoint was a gain in BCVA 6 months after the first intravitreal treatment. Secondary endpoints were central retinal thickness and the safety of the procedure.

\section{Statistical Analysis}

Data were collected using Microsoft Excel spreadsheets (Microsoft Excel 2003) and statistical analysis was performed using SPSS (IBM SPSS Version 19). Student's t test and Wilcoxon rank test were used to compare both data cohorts and to calculate significance. A p value below 0.05 was considered significant. All tests were two-sided.

\section{Results}

\section{Efficacy}

At baseline, mean BCVA was 22.4 letters (SD \pm 12.3 letters) in CRVO and 26.3 letters (range 9.9 letters) in BRVO patients in group 1 , and $15.5 \pm 10.6$ letters versus $28.5 \pm 10.3$ letters in group 2, respectively. Mean macular thickness was found to be $604.4 \mu \mathrm{m}$ (range \pm 230.5 $\mu \mathrm{m}$ ) in CRVO and $500.5 \mu \mathrm{m}$ (range $\pm 106 \mu \mathrm{m}$ ) in BRVO patients in group 1 and $601.1 \mu \mathrm{m}$ (range $\pm 252.5 \mu \mathrm{m}$ ) versus $469.8 \mu \mathrm{m}$ (range $\pm 151.7 \mu \mathrm{m}$ ) in group 2 .

In group 1, at 6 months after initiation of therapy an increase in BCVA ( \pm 1 standard deviation) of $2.5( \pm 1.6)$ letters was observed in CRVO (fig. 2a, 3a, b) and of 13.0 $( \pm 3.2)$ letters in BRVO patients (fig. 2b). In group 2, CRVO patients showed an increase in BCVA ( \pm 1 standard deviation) of $5.9( \pm 0.4)$ letters (fig. 2a) compared to $3.8( \pm 2.4)$ letters in BRVO patients (fig. $2 \mathrm{~b}$ ). When comparing the two treatment groups with respect to the subtype of vein occlusion, there was no significant difference after 6 months, except for BRVO patients treated with the dexamethasone implant alone (BRVO patients in group $1, \mathrm{p}=0.005$, fig. $2 \mathrm{~b}$ ). However, comparing area under the curve analyses, highest values could only be obtained in CRVO patients using the combined therapy regimen $(65.4$ vs. $56.8, \mathrm{p}<0.05)$. In BRVO no marked differences could be found (34.8 vs. 33.4, $\mathrm{p}=0.40)$ in this follow-up period. The maximum treatment effect in terms of visual gain was seen after the first month, after the dexamethasone implantation as well as after the first injection of bevacizumab. There was a nonsignificant difference in gain of BCVA comparing the two treatment modalities in CRVO patients (fig. 2a). 


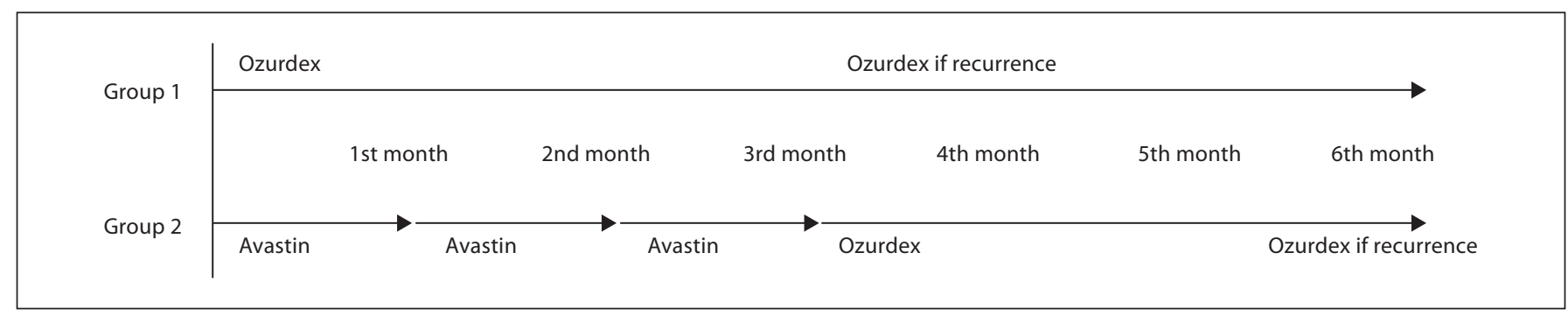

Fig. 1. Treatment strategy (timeline): primary dexamethasone implant therapy (group 1) versus bevacizumab pretreatment and subsequent dexamethasone implant therapy (group 2). During the study period, recurrence was treated in both groups at a loss of visual acuity of $>5$ letters (ETDRS) and/or increase of central retinal thickness in OCT measurements of more than $100 \mu \mathrm{m}$.
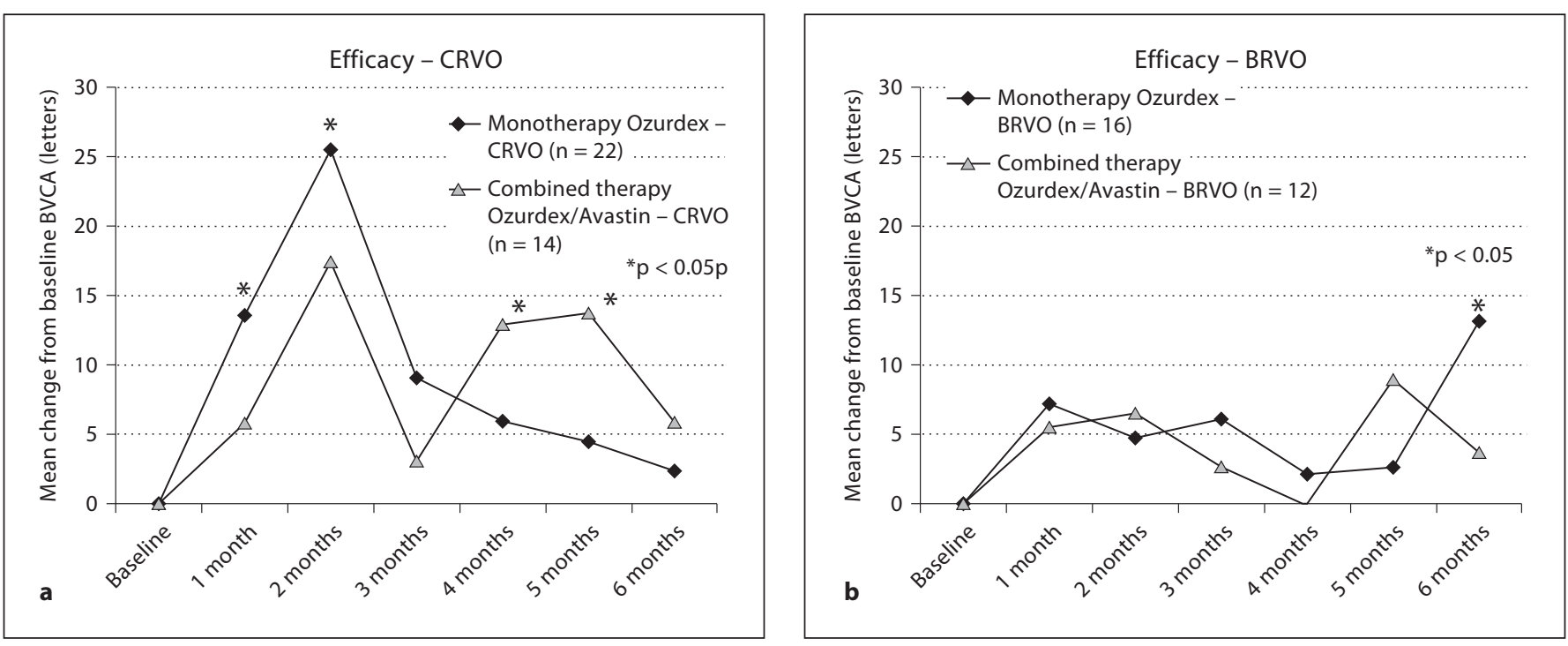

Fig. 2. a, b Visual acuity compared to baseline: 6-month follow-up in both treatment groups after initial therapy in patients with CRVO (a) and BRVO (b).

OCT measurements showed a significant reduction of central retinal thickness after 6 months in group 1, both for CRVO patients ( $p=0.01$, fig. $4 a, 5)$ and BRVO patients $(\mathrm{p}=0.003$, fig. $4 \mathrm{~b})$. No effect was seen at 6 months for CRVO and BRVO patients in group 2.

In group 1, 16/22 (72.7\%) CRVO patients experienced a recurrence after a mean period of $3.8( \pm 1.25)$ months versus $6 / 16(37.5 \%)$ BRVO patients after a mean period of $3.5( \pm 0.63)$ months after the first dexamethasone implant. In group 2, recurrences after the first dexamethasone implant (following three consecutive injections of bevacizumab) occurred after a mean follow-up of 3.2 $( \pm 0.5)$ months in 9/14 (64.3\%) CRVO patients, and after
$3.7( \pm 0.75)$ months in $7 / 12(58.3 \%)$ BRVO patients (table 1).

During the entire period of 6 months, the total number of retreatments using dexamethasone implant was $25 / 38(65.8 \%)$ in group 1 versus $24 / 26$ in group 2 (92.3\%).

\section{Safety}

Before initiation of treatment intraocular pressure was within the normal range in all patients. A relevant increase in intraocular pressure was defined as an increase of $>5 \mathrm{~mm} \mathrm{Hg}$ compared to baseline. During the 6-month follow-up, 22/38 (57.9\%) patients in group 1 experienced an increase in intraocular pressure (14/22 CRVO patients, 

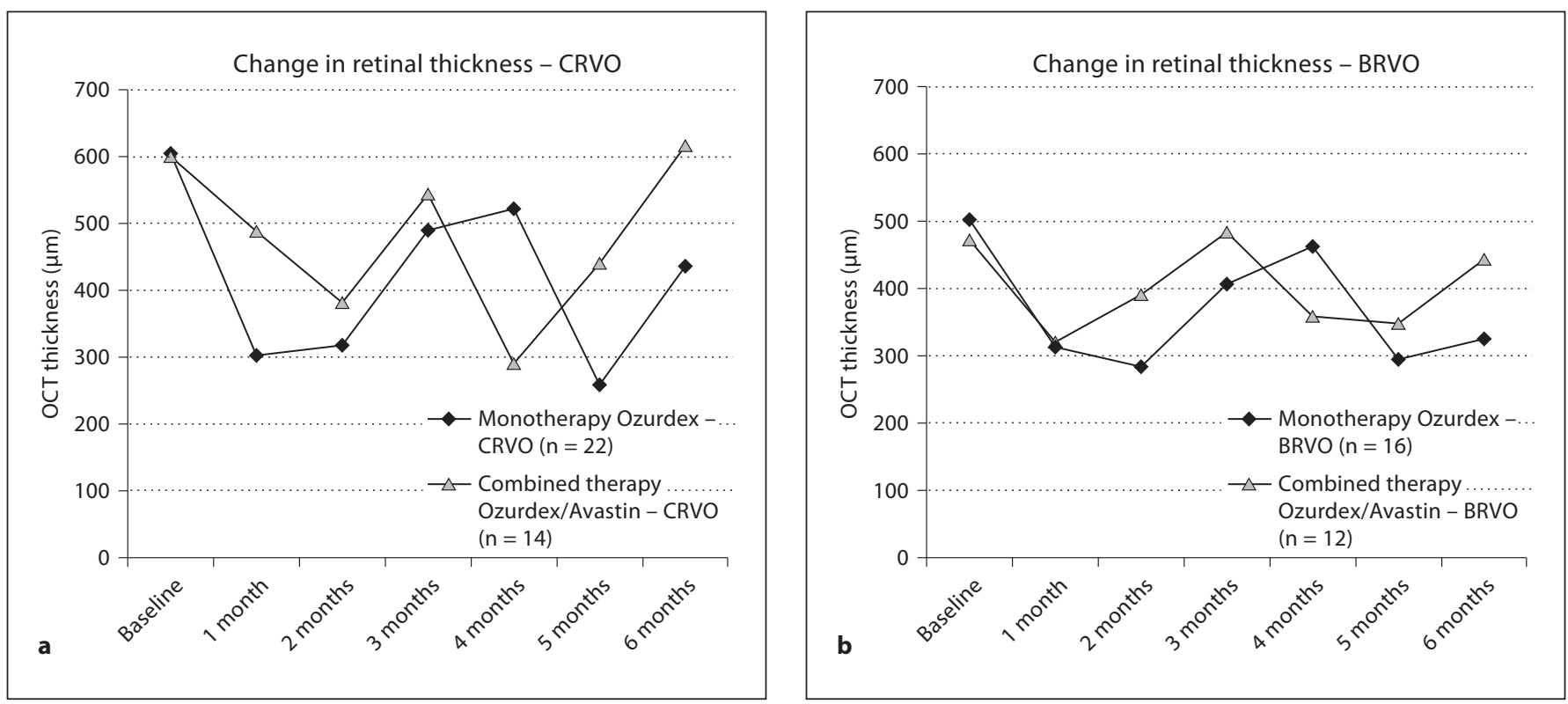

Fig. 3. a, b Change in retinal thickness using spectral domain OCT: 6-month follow-up in both treatment groups after initial therapy in patients with CRVO (a) and BRVO (b).

Table 1. Overview of the 6-month follow-up of all groups after primary intravitreal therapy

\begin{tabular}{|c|c|c|c|c|c|c|c|}
\hline & \multicolumn{2}{|c|}{ BCVA (ETDRS) } & \multirow{2}{*}{$\begin{array}{l}\text { Recurrence } \\
\text { (n/months) }\end{array}$} & \multicolumn{2}{|c|}{ OCT $(\mu \mathrm{m})$} & \multirow{2}{*}{$\begin{array}{l}\text { IOP }(\mathrm{n} / \%) \\
\text { increase }> \\
5 \mathrm{~mm} \mathrm{Hg}\end{array}$} & \multirow{2}{*}{$\begin{array}{l}\text { Advers } \\
\text { events }\end{array}$} \\
\hline & PreOP & 6 months & & PreOP & 6 months & & \\
\hline Monotherapy Ozurdex - CRVO (n = 22) & 22.4 & 24.9 & $16 / 3.8$ & 604.4 & 438.1 & $14 / 63.6$ & 1 \\
\hline Monotherapy Ozurdex - BRVO $(\mathrm{n}=16)$ & 26.3 & 39.2 & $6 / 3.5$ & 500.5 & 324.8 & $08 / 50.0$ & 0 \\
\hline Combined therapy Ozurdex/Avastin - CRVO $(n=14)$ & 15.5 & 21.4 & $9 / 3.2$ & 543.1 & 436.7 & $08 / 57.1$ & 0 \\
\hline Combined therapy Ozurdex/Avastin - BRVO $(n=12)$ & 28.6 & 32.4 & $7 / 3.7$ & 479.6 & 422.3 & $06 / 50.0$ & 0 \\
\hline
\end{tabular}

$63.6 \% ; 8 / 16$ BRVO patients, 50\%). In group 2, an increase in intraocular pressure was seen in $14 / 26(53.8 \%)$ patients, 8/14 (57.1\%) CRVO, and 6/12 (50.0\%) BRVO patients (table 1). Intraocular pressure exceeding the normal range was controlled by topical drugs. One eye in group 1 required cyclophotocoagulation after the second dexamethasone implant.

In 1 CRVO patient of group 1 localized retinal detachment occurred 3 weeks after implantation, which was successfully reattached with a scleral buckle. No other adverse events such as intravitreal hemorrhage or endophthalmitis were noted. No accelerated cataract formation was noted. Sixteen patients were pseudophakic at study entry.

Two Treatment Regimens for RVO

\section{Discussion}

Until recently, our treatment strategy for patients with BRVO and CRVO was mainly based on the results of BRVO and CRVO trials $[8,9]$, suggesting deferred focal laser for macular edema in BRVO patients with BCVA below 20/40. Peripheral laser was advocated in cases with severe ischemia in BRVO and CRVO in order to treat or prevent neovascularization at the posterior or anterior segment of the eye and to prevent neovascular glaucoma, especially in CRVO. We knew that laser photocoagulation of the macular region had no benefit for macular function in eyes with CRVO at all [8].

In contrast, since the advent of pharmacological treatment options including the intravitreal application of 


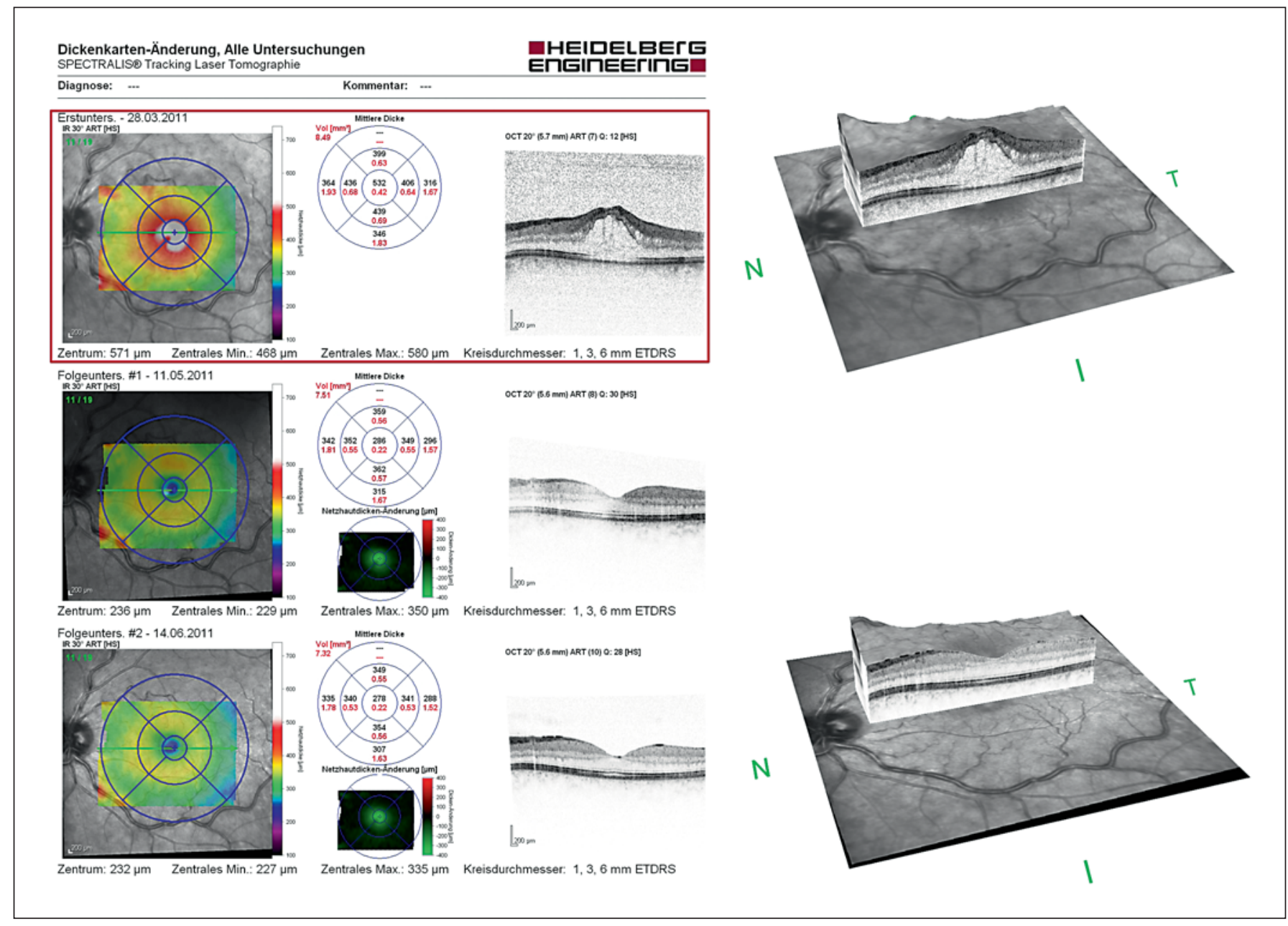

Fig. 4. Spectralis-OCT images of the macular area of a CRVO case: 3-month course of primary dexamethasone implant therapy.

corticosteroids $[6,7]$ and anti-VEGF drugs $[5,10]$, patients with RVO, both CRVO and BRVO, have a better chance of visual recovery.

Both pharmacological approaches address important issues in the pathogenesis of retinal vascular occlusion, such as the expression of VEGF in the vitreous [11] and inflammatory processes [12-16]. Corticosteroids not only have an anti-inflammatory effect (e.g. inhibition of fibrin deposition, leukocyte movement, suppression of homing and migration of inflammatory cells), but also interfere with the synthesis of VEGF and other cytokines $[2,17]$.

Dexamethasone is a potent, water-soluble corticosteroid which can be delivered into the vitreous cavity either by injection of a dexamethasone solution with a very short half-life [18], or by the implantation of an approved dexamethasone intravitreal implant using a customized applicator system (Ozurdex, Allergan, Inc., Irvine, Calif., USA) [6]. Dexamethasone is then released over a prolonged period of up to 6 months until complete resolution of the matrix, and has a beneficial effect on visual acuity and retinal thickness in patients with macular edema associated with BRVO and CRVO [6].

Anti-VEGF drugs, such as ranibizumab, also have a beneficial effect on visual function and reduce central macular thickness in BRVO and CRVO eyes $[5,10,19,20]$. However, with respect to the shorter half-life of ranibizumab [21] numerous injections are required to achieve and maintain this therapeutic effect. Of note, ranibizumab was not approved for the treatment of RVO at the be- 

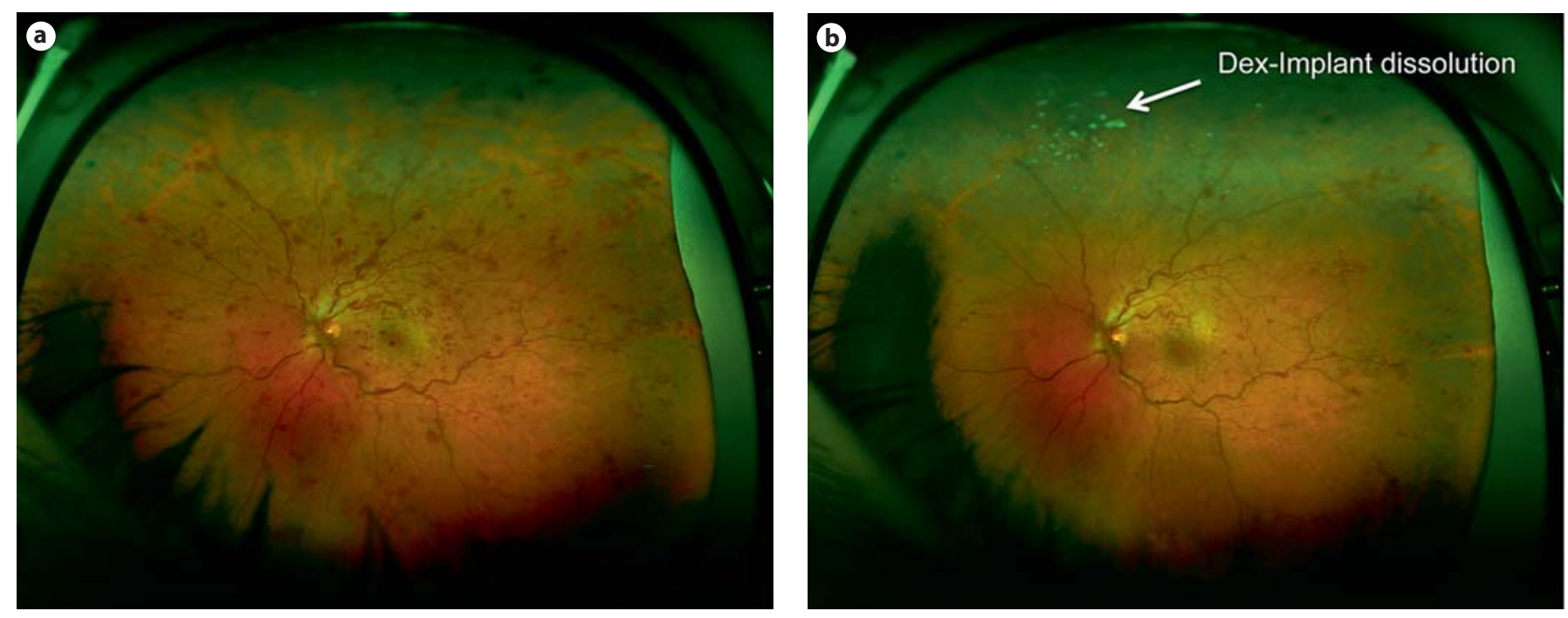

Fig. 5. a, b Fundus documentation (Optomap) of a patient with CRVO before (a) and 3 months after (b) primary dexamethasone implant therapy.

ginning of this study. Therefore, bevacizumab was used for treatment in an off-label setting after IRB approval.

The aim of the present study was to compare the efficacy of these two treatment regimens and to assess whether the initial treatment with an anti-VEGF drug has an impact on the interval until the recurrence of macular edema.

We observed that pretreatment with 3 doses of bevacizumab in combination followed by a single dexamethasone implant was not effective in prolonging this interval compared to monotherapy using the dexamethasone implant in the first instance. Recurrences occurred between 3.2 and 3.8 months and were in line with the known pharmacokinetics of the dexamethasone implant and the results of the GENEVA trial, which revealed a decrease in the treatment effect at about 3-4 months after implantation [6]. Interestingly, the number of recurrences (and subsequent retreatments) in patients receiving monotherapy with the dexamethasone implant was lower in BRVO compared to CRVO patients, which may well be explained by the more favorable natural history of macular edema associated with BRVO. Therefore, considering the potential adverse effect of a corticosteroidal implant, BRVO patients seem better candidates for this treatment as a first-line option compared to CRVO patients, as the latter require more retreatments as described in other trials, too $[10,19]$.

Furthermore, monotherapy using the dexamethasone implant was especially beneficial in BRVO patients and led to a significant gain of 13.0 letters in contrast to CRVO patients with a gain of only 2.5 letters. However, area under the curve analyses showed no marked differences in BRVO patients. In contrast, the combination therapy led to better functional improvement in CRVO patients (5.9 letters) when compared to monotherapy.

We are aware that the study population was limited and the baseline data range for all subjects was at a higher level concerning BCVA and OCT measurements compared to the GENEVA trial. Therefore, the improvement of visual acuity (gain in letters) after retreatment with the dexamethasone implant was not as high as that observed in the GENEVA trial.

As expected for a corticosteroid, we observed elevation of intraocular pressure, which was controlled by antiglaucomatous topical drops in all cases except 1 case, that underwent cyclophotocoagulation after the second dexamethasone implant. In patients receiving monotherapy intraocular pressure was found to be elevated during follow-up in $63.6 \%$ of CRVO eyes, and $50 \%$ of BRVO eyes, compared to $57.1 \%$ in CRVO, and $50.0 \%$ in BRVO eyes pretreated with bevacizumab. This raises the question whether the subsequent implantation of a dexamethasone implant after a period of 3-4 months increases the risk of intraocular pressure elevation, when the partially degraded first implant still releases the drug into the vitreous cavity. In contrast, in the GENEVA trial no such additional effect could occur, because reinjection was not permitted within 6 months. The same considerations may theoretically apply for the formation of cataract in 
phakic eyes. Therefore, the combination of a dexamethasone implant with an anti-VEGF drug or a switch from dexamethasone monotherapy to an anti-VEGF strategy may be an option in selected cases, e.g. especially in CRVO patients, where the natural history is quite poor compared to patients with BRVO and more treatments seem to be required to maintain function $[10,19]$.

The limitation of the present study is the relatively short period of follow-up. However, our aim was to investigate the response to two different treatment options in patients with RVO. We are aware that the results seen for bevacizumab may not necessarily be transferred to the results one may obtain using ranibizumab in a similar setting. Of note, ranibizumab was not approved for the treatment of RVO at the start of our trial. A longer period of review will be needed to document the sustainability of the treatment benefit using dexamethasone monotherapy especially in BRVO patients. In addition, especially the safety issues such as secondary glaucoma and cataract progression need to be investigated over a prolonged period of follow-up. Cataract progression was not significant in this short follow-up period and did not affect visual acuity outcome measurements, and might not have progressed as described in other studies [7] due to the limited follow-up of our investigation. However, our trial is among the first to investigate the combination of an anti-VEGF treatment and the dexamethasone slow-release implant.

\section{References}

1 Rehak J, Rehak M: Branch retinal vein occlusion: pathogenesis, visual prognosis, and treatment modalities. Curr Eye Res 2008;33: 111-131.

2 Antonetti DA, Barber AJ, Khin S, Lieth E, Tarbell JM, Gardner TW: Vascular permeability in experimental diabetes is associated with reduced endothelial occludin content: vascular endothelial growth factor decreases occludin in retinal endothelial cells. Penn State Retina Research Group. Diabetes 1998; 47:1953-1959.

3 Campochiaro PA, Hafiz G, Shah SM, Nguyen QD, Ying H, Do DV, Quinlan E, Zimmer-Galler I, Haller JA, Solomon SD, Sung JU, Hadi Y, Janjua KA, Jawed N, Choy DF, Arron JR: Ranibizumab for macular edema due to retinal vein occlusions: implication of VEGF as a critical stimulator. Mol Ther 2008; 16:791-799.

4 Shahsuvaryan ML, Melkonyan AK: Central retinal vein occlusion risk profile: a casecontrol study. Eur J Ophthalmol 2003;13: 445-452.

5 Brown DM, Campochiaro PA, Singh RP, Li Z, Gray S, Saroj N, Rundle AC, Rubio RG, Murahashi WY: Ranibizumab for macular edema following central retinal vein occlusion: six-month primary end point results of a phase III study. Ophthalmology 2010;117: 1124-1133.

6 Haller JA, Bandello F, Belfort R Jr, Blumenkranz MS, Gillies M, Heier J, Loewenstein A, Yoon YH, Jacques ML, Jiao J, Li XY, Whitcup SM: Randomized, sham-controlled trial of dexamethasone intravitreal implant in patients with macular edema due to retinal vein occlusion. Ophthalmology 2010;117:11341146.

7 Haller JA, Bandello F, Belfort R Jr, Blumenkranz MS, Gillies M, Heier J, Loewenstein A, Yoon YH, Jiao J, Li XY, Whitcup SM: Dexa- methasone intravitreal implant in patients with macular edema related to branch or central retinal vein occlusion twelve-month study results. Ophthalmology 2011;118: 2453-2460.

8 Evaluation of grid pattern photocoagulation for macular edema in central vein occlusion. The Central Vein Occlusion Study Group M report. Ophthalmology 1995;102:14251433.

9 Argon laser photocoagulation for macular edema in branch vein occlusion. The Branch Vein Occlusion Study Group. Am J Ophthalmol 1984;98:271-282.

10 Brown DM, Campochiaro PA, Bhisitkul RB, Ho AC, Gray S, Saroj N, Adamis AP, Rubio RG, Murahashi WY: Sustained benefits from ranibizumab for macular edema following branch retinal vein occlusion: 12-month outcomes of a phase III study. Ophthalmology 2011;118:1594-1602.

11 Adamis AP, Miller JW, Bernal MT, D’Amico DJ, Folkman J, Yeo TK, Yeo KT: Increased vascular endothelial growth factor levels in the vitreous of eyes with proliferative diabetic retinopathy. Am J Ophthalmol 1994;118: 445-450.

12 Kaneda S, Miyazaki D, Sasaki S, Yakura K, Terasaka Y, Miyake K, Ikeda Y, Funakoshi T, Baba T, Yamasaki A, Inoue Y: Multivariate analyses of inflammatory cytokines in eyes with branch retinal vein occlusion: relationships to bevacizumab treatment. Invest Ophthalmol Vis Sci 2011;52:2982-2988.

13 Ki IY, Arimura N, Noda Y, Yamakiri K, Doi N, Hashiguchi T, Maruyama I, Shimura M, Sakamoto T: Stromal-derived factor-1 and inflammatory cytokines in retinal vein occlusion. Curr Eye Res 2007;32:1065-1072.

14 Noma H, Funatsu H, Harino S, Mimura T, Eguchi S, Hori S: Vitreous inflammatory factors in macular edema with central reti- nal vein occlusion. Jpn J Ophthalmol 2011; 55:248-255.

15 Noma H, Funatsu H, Mimura T, Shimada K: Increase of aqueous inflammatory factors in macular edema with branch retinal vein occlusion: a case control study. J Inflamm (Lond) 2010;7:44.

16 Okunuki Y, Usui Y, Katai N, Kezuka T, Takeuchi M, Goto H, Wakabayashi Y: Relation of intraocular concentrations of inflammatory factors and improvement of macular edema after vitrectomy in branch retinal vein occlusion. Am J Ophthalmol 2011;151: 610-616.

17 Nauck M, Karakiulakis G, Perruchoud AP Papakonstantinou E, Roth M: Corticosteroids inhibit the expression of the vascular endothelial growth factor gene in human vascular smooth muscle cells. Eur J Pharmacol 1998;341:309-315.

18 Nabih M, Peyman GA, Tawakol ME, Naguib $\mathrm{K}$ : Toxicity of high-dose intravitreal dexamethasone. Int Ophthalmol 1991;15:233235.

19 Campochiaro PA, Brown DM, Awh CC, Lee SY, Gray S, Saroj N, Murahashi WY, Rubio RG: Sustained benefits from ranibizumab for macular edema following central retinal vein occlusion: twelve-month outcomes of a phase III study. Ophthalmology 2011;118: 2041-2049.

20 Campochiaro PA, Heier JS, Feiner L, Gray S, Saroj N, Rundle AC, Murahashi WY, Rubio RG: Ranibizumab for macular edema following branch retinal vein occlusion: sixmonth primary end point results of a phase III study. Ophthalmology 2010;117:11021112.

21 Bakri SJ, Snyder MR, Reid JM, Pulido JS, Ezzat MK, Singh RJ: Pharmacokinetics of intravitreal ranibizumab (Lucentis). Ophthalmology 2007;114:2179-2182. 